\title{
A 55-kDa Calcium Dependent Protein Kinase Phosphorylated Thr Residues from the Auto-Regulatory Domain of Plasma Membrane $\mathbf{H}^{+}$-ATPase in Rice
}

\author{
Tetsuya OOKURA ${ }^{1 *}$, Setsuko KOMATSU ${ }^{2}$, Yukio KAWAMURA ${ }^{3}$ and \\ Kunihiro KASAMO ${ }^{4}$ \\ 1,3 Food Function Division, National Food Research Institute (Tsukuba, Ibaraki 305-8642, Japan) \\ 2,4 Department of Molecular Genetics, National Institute of Agrobiological Sciences \\ (Tsukuba, Ibaraki 305-8602, Japan) \\ ${ }^{4}$ Resource Institute of Botany, Okayama University (Kurashiki, Okayama 710-0046, Japan)
}

\begin{abstract}
Plasma membrane $\mathrm{H}^{+}$-ATPases play important roles in plant growth by keeping a proton gradient across the membrane. Although cold or pathogen stress affects the activity of the $\mathrm{H}^{+}$-ATPase and plant growth, its regulatory mechanisms are not fully elucidated. A rice $55-\mathrm{kDa}$ calcium-dependent protein kinase was activated on cold treatment and pathogen infection. Here we showed that the kinase phosphorylated two Thr residues in the auto-regulatory domain of the $\mathrm{H}^{+}$-ATPase in vitro. Phosphorylation of these Thr residues might contribute to the ATPase activity regulation during cold or pathogen stress.
\end{abstract}

Discipline: Biotechnology

Additional key words: ATPase activity, cold stress

\section{Introduction}

Plasma membrane $\mathrm{H}^{+}$-translocating ATPases $\left(\mathrm{H}^{+}\right.$ATPases) from plants are electrogenic proton pumps which regulate intracellular $\mathrm{pH}$ and nutrient uptake. The control of $\mathrm{H}^{+}$-ATPase activity is critical to plant growth. Proteolytic digestion of the $\mathrm{H}^{+}$-ATPases clarified that the trypsin cleavable $\mathrm{C}$-terminal region (auto-regulatory domain; 100 amino acids) regulated ATPase activity. $\mathrm{N}$-terminal side of the auto-regulatory domain (Region I) and extreme C-terminal part of the domain (Region II) have been reported to have different effects on the ATPase activity. Extensive analysis on Region II revealed that phosphorylation of the penultimate $\mathrm{Thr}$ residue in the C-terminal end resulted in binding of 14-3-3 proteins towards the Region II, which led to constitutive activation of the ATPase activity ${ }^{4,5}$. Although Region I peptide suppressed the enhancement of the ATPase activity by trypsin cleavage $^{19}$, the regulatory mechanism remains to be elucidated.

It has been suggested that membrane-bound forms of $\mathrm{Ca}^{2+}$-dependent protein kinases (CDPKs) phosphorylate the $\mathrm{H}^{+}$-ATPases. Evidence for the calcium-dependent phosphorylation of the $\mathrm{H}^{+}$-ATPases has been accumulated in studies on the beet $\operatorname{root}^{13}$, fava bean guard cells ${ }^{20}$ and oat root ${ }^{21}$. In rice, a 55-kDa CDPK has been reported to function near the plasma membrane on cold stress treatment ${ }^{12}$ and pathogen infection ${ }^{11}$. The substrates for the 55-kDa CDPK are, however, largely unknown. The mechanism for growth retardation associated with cold or pathogen stress remains to be elucidated.

Here we report that the antibody against the Region I peptide augmented the ATPase activity in vitro and the 55-kDa CDPK phosphorylated two Thr residues in the peptides from the Region I in a calcium dependent manner. These results might clarify the regulatory mechanism of the ATPases activity by CDPK and lead to understanding how cold or pathogen stress affects rice growth through regulation of the electrogenic $\mathrm{H}^{+}$-ATPase pump.

\footnotetext{
Present address:

${ }^{3}$ Department of Food and Nutrition, Kinki University (Nakamachi, Nara 631-8505, Japan)

*Corresponding author: fax +81-29-838-7319; e-mail ookura@nfri.affrc.go.jp

Received 26 August 2004; accepted 15 November 2004.
} 


\section{Materials and methods}

\section{Chemicals}

Fmoc-amino acids (Fmoc, fluorene-9-ylmethoxycarbonyl) were purchased from Nova Biochem (Tokyo, Japan). $\left[\gamma_{-}{ }^{32} \mathrm{P}\right]$ ATP was obtained from Amersham Biosciences (Piscataway, NJ, USA).

\section{Peptide preparation and antibody production}

Auto-regulatory domain peptides and mock peptides were synthesized on HMP (Hydroxy-methylphenoxymethyl) resin or MAP (Multiple antigen peptide) resin with a peptide synthesizer (430A, Applied Biosystems, Foster City, CA, USA) using Fmoc-amino acids. The protected residues were deblocked in trifluoroacetic acid (TFA) in the presence of thioanisole and two additional scavengers, m-cresol and ethanedithiol. Each peptide was purified through reversed phase HPLC on an ODS column with a linear gradient of $0 \%$ to $60 \%$ acetonitrile in $0.1 \%$ TFA for 60 min or gel chromatography using Sephadex G-50 (Amersham Biosciences) for MAP resins as described previously ${ }^{17}$. The amino acid sequence of peptides was determined with a gas-phase protein sequencer (473A, Applied Biosystems). Peptide quantities were determined by using an amino acid analyzer (Hitachi 5500, Tokyo, Japan). The purified MAP peptide, containing the amino acid sequence (RIAFTRKKDFGTQEN QLKWATAQRTI; AR-1), was used to raise an antibody in mice with Freund's adjuvant using a standard protocol. Mouse sera were purified by ammonium sulfate precipitation. Antibody concentration was determined by protein assay kit (Biorad, Herculs, CA, USA) using bovine serum albumin as a standard.

\section{ATPase activity measurement with trypsin or antibody treatment}

ATPase activity was measured as described previously $^{8}$. Antibody or trypsin and $27.5 \mu \mathrm{g}$ solubilized ATPase were mixed and preincubated at $38^{\circ} \mathrm{C}$ for $30 \mathrm{~min}$ in $30 \mu \mathrm{L}$ ATPase reaction mixture containing $3 \mathrm{mM}$ TrisATP, $3 \mathrm{mM} \mathrm{MgSO}_{4}, 50 \mathrm{mM} \mathrm{KCl}, 2 \mathrm{mM}$ gramicidin $\mathrm{D}, 1$ $\mathrm{mM}$ sodium azide and $1 \mathrm{mM}$ ammonium molybdate in 30 $\mathrm{mM} \mathrm{MES/Tris} \mathrm{(pH} \mathrm{6.5).} \mathrm{In} \mathrm{the} \mathrm{case} \mathrm{of} \mathrm{trypsin} \mathrm{treatment,}$ protease digestion was terminated by addition of trypsin inhibitor $(50 \mu \mathrm{g}$ eq. $)$ prior to the addition of ATPase reaction mixture $(0.5 \mathrm{~mL})$. Inorganic phosphate production by ATPase was measured in the presence of $0.02 \%$ asolectin during incubation at $38^{\circ} \mathrm{C}$ for $30 \mathrm{~min}$.

\section{A 55-kDa calcium dependent protein kinase preparation from rice}

The crude extract from rice leaves was prepared according to the method of Kanematsu' ${ }^{6}$ A $55-\mathrm{kDa}$ CDPK was partially purified through DEAE MemSep 1010 column (Millipore, Bedford, MA, USA), Sephacryl S-200 (1,000 × $21 \mathrm{~mm}$, Amersham Biosciences $)$ and Threonine-Sepharose column $(40 \times 26 \mathrm{~mm}$, Amersham Biosciences) as previously reported ${ }^{7}$. This fraction was used as a 55-kDa CDPK fraction.

\section{In vitro phosphorylation of Region I peptide by calcium dependent protein kinases}

The in vitro phosphorylation assay was carried out in a reaction mixture $(40 \mu \mathrm{L})$ containing $20 \mathrm{mM}$ Tris- $\mathrm{HCl}$ (pH 7.5), $10 \mathrm{mM} \mathrm{MgCl}, 200 \mu \mathrm{M} \mathrm{CaCl}_{2}, 34.2 \mu \mathrm{M}$ $\left[\gamma-{ }^{32} \mathrm{P}\right]$ ATP $(0.44 \mathrm{TBq} / \mathrm{mmol}), 5 \mu \mathrm{L}$ protein kinase and 2 $\mu \mathrm{g}$ histone III-S (Sigma, St. Louis, MO, USA) or 1 nmole peptide. The basal level of substrate phosphorylation was measured in the presence of $4 \mathrm{mM}$ EGTA instead of $\mathrm{CaCl}_{2}$. The reaction mixture was incubated for $15 \mathrm{~min}$ at $30^{\circ} \mathrm{C}$ and terminated by addition of SDS-PAGE sample buffer. After in vitro phosphorylation, the proteins were separated by low bis SDS-PAGE and stained with Coomassie brilliant blue (CBB) as previously described ${ }^{7}$. The gel was destained, dried and exposed to autoradiography on an X-ray film (Kodak, Rochester, NY) at $-80^{\circ} \mathrm{C}$ for 2 days.

\section{Assay of protein kinase activity}

Protein kinase activity was assayed in a reaction mixture $(100 \mu \mathrm{L})$ containing $20 \mathrm{mM}$ Tris- $\mathrm{HCl}$ (pH 7.5), $10 \mathrm{mM} \mathrm{MgCl}, 0.4 \mu \mathrm{g} / \mathrm{mL}$ histone III-S or 1 nmole peptide, $200 \mu \mathrm{M} \mathrm{CaCl}, 34.2 \mathrm{mM}\left[\gamma_{-}{ }^{32} \mathrm{P}\right] \mathrm{ATP}(110 \mathrm{TBq} /$ $\mathrm{mmol}$ ) and $5 \mu \mathrm{L}$ of rice protein kinase fraction. The basal level of substrate phosphorylation was measured in the presence of $4 \mathrm{mM}$ EGTA instead of $\mathrm{CaCl}_{2}$. The reaction mixture was incubated for $15 \mathrm{~min}$ at $30^{\circ} \mathrm{C}$ and terminated by cooling to $0^{\circ} \mathrm{C}$. Then $75 \mu \mathrm{L}$ of reaction mixture was applied onto a P-81 filter (Whatman, Maidstone, UK). The filters were washed with water followed by ethanol, then dried. Radioactivity was determined by a Cherenkov counting.

\section{Results and discussion}

\section{ATPase activity modulation by trypsin and antibody treatment}

The auto-regulatory domain cleavage by trypsin in oat root and sugar beet leaf $\mathrm{H}^{+}$-ATPase resulted in increasing ATPase activity ${ }^{18,19}$. Fig. 1 shows the possible modes of $\mathrm{H}^{+}$-ATPase regulation by proteolytic digestion, phosphorylation and antibody treatment on the auto-regulatory domain. Treatment of the rice $\mathrm{H}^{+}$-ATPase with 5 $\mu \mathrm{g}$ trypsin gave maximal augmentation of the ATPase 


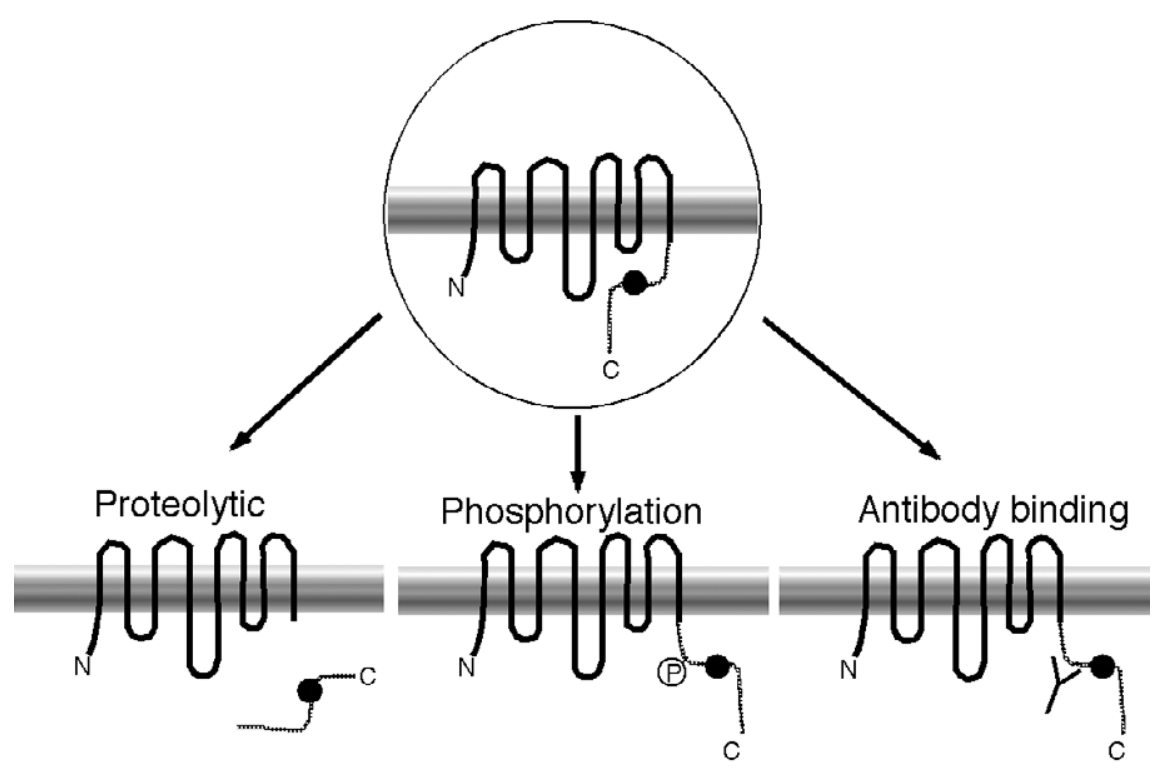

Fig. 1. Possible modes of the $\mathrm{H}^{+}$-ATPase activity regulation by the $\mathrm{C}$-terminal auto-regulatory domain The auto-regulatory domain in the C-terminal (hatched lines) was believed to interact with another domain to inhibit ATPase activity. Proteolytic digestion of the domain and phosphorylation in the extreme $\mathrm{C}$-terminal $\mathrm{Thr}$ residues resulted in increasing $\mathrm{H}^{+}$-ATPase activity.

A

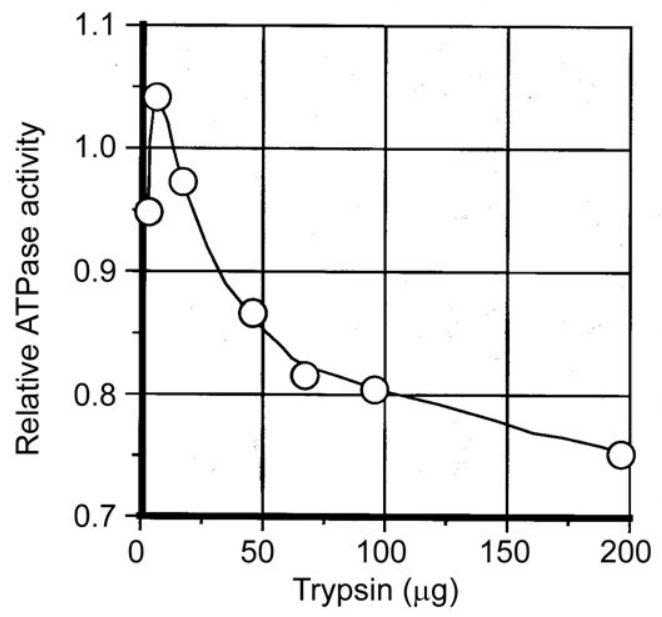

$\mathrm{B}$

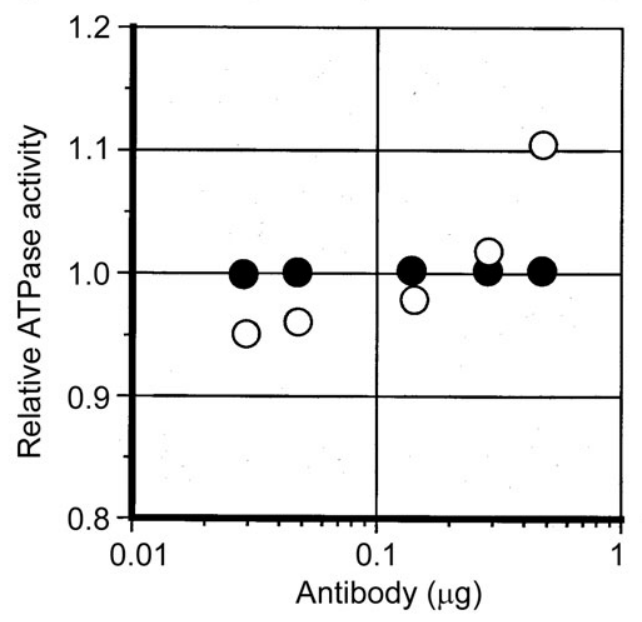

Fig. 2. ATPase activity modulation by trypsin and anti-AR-1 peptide antibody treatment

$27.5 \mu \mathrm{g}$ of solubilized ATPase in the ATPase reaction mixture was treated with either trypsin (A) or anti-AI-1 antibody (B). In the case of trypsin treatment (A), maximal augmentation was observed at $5 \mu \mathrm{g}$ trypsin treatment. On antibody treatment (B), open circles represented the activity change of the ATPase by the addition of the anti-AR-1 peptide antibody. Filled circles represented the activity for addition of equivalent control mouse IgG.

activity (Fig. 2A). Activity decrease on treatment with over $50 \mu \mathrm{g}$ trypsin might be due to other domain proteolytic cleavage. Addition of anti-AR-1 peptide (RIAFTRKKDFGTQENQLKWATAQRTI) antibody (0.5 $\mu \mathrm{g}$; open circle) led to augmented ATPase activity (110\%), while control mouse IgG addition (filled circles) did not have an affect on the ATPase activity (Fig. 2B). These results indicated that the AR-1 sequence had an inhibitory effect on ATPase activity. This fact was consistent with the report that external addition of the autoregulatory domain peptide (AFTMKKDYGKKEEREAQ WALAQRTLHGLQ) suppressed the ATPase activity of 
the trypsin-activated ATPase ${ }^{19}$. These results strongly suggest that the AR-1 peptide region in the auto-regulatory domain plays an inhibitory role in regulating ATPase activity.

Calcium dependent phosphorylation and de-phosphorylation of the $\mathrm{H}^{+}$-ATPases have been reported ${ }^{1}$. Considering that the auto-regulatory domain was easily cleaved by trypsin and was bound by the anti-AR-1 antibody, we assumed that this domain was likely to be accessible to calcium dependent protein kinases (CDPKs). The rice 55-kDa CDPK was localized at the membrane fraction on cold treatment ${ }^{12}$ and pathogen infection $^{11}$. Thus we next analyzed whether the AR-1 peptide was phosphorylated by the 55-kDa CDPK.

\section{AR-1 phosphorylation by CDPK in vitro}

We analyzed whether the 55-kDa CDPK phosphorylated the AR-1 related peptides, which were based on the peptide sequence in the Region I of the auto-regulatory domain of the rice $\mathrm{H}^{+}$-ATPase (OSA2) ${ }^{16}$, with two methods. First we analyzed phosphorylation of the AR-1 using SDS-PAGE and autoradiography. Lane 1 in Fig. 3 showed the CBB-staining of AR-1 (indicated by a closed rectangular). Lanes 4 and 5 showed that the AR-1 was phosphorylated in the presence of $200 \mu \mathrm{M} \mathrm{CaCl}_{2}$ (lane 5), but not in the absence of $\mathrm{CaCl}_{2}$ (lane 4). AR-1 had, however, no phosphorylating activity by itself (lane 3 ). These results indicated that the $55-\mathrm{kDa}$ CDPK phosphorylated the AR-1 in a calcium dependent manner. Lane 5 contained a faint band (indicated by an arrow) above the main band. The Chou and Fasman method predicted that the AR- 1 was able to form an $\alpha$-helix structure ${ }^{2}$. The faint band might be AR-1 aggregates through helix to helix interactions.

Next, we determined which Thr residues in the AR1 sequence were phosphorylated by the $55-\mathrm{kDa}$ CDPK.
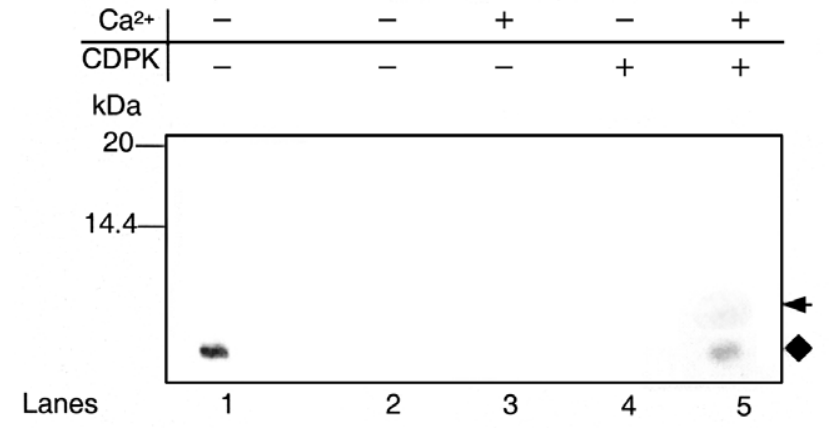

Fig. 3. AR-1 peptide (RIAFTRKKDFGTQENQLKWATA QRTI) was phosphorylated in a calcium-dependent manner

Lane 1: CBB staining of the AR-1. Lanes 2 to 5: Autoradiodiagram of the AR-1 peptide. The AR-I peptide was incubated with $\mathrm{CaCl}_{2}$ (lanes 3 and 5) or without $\mathrm{CaCl}_{2}$ (lanes 2 and 4) in the presence of protein kinase fraction (lanes 4 and 5) or the absence of protein kinase fraction (lanes 2 and 3). A filled rectangular showed the AR-I peptide location. An arrow showed a supposed AR-1 aggregate in lanes 1 and 5.

Five kinds of peptides (AR-1 to AR-5, Table 1) were subjected to the in vitro phosphorylation assay. Table 1 showed that AR-1, AR-3 and AR-4 were phosphorylated in a calcium dependent manner. All three peptides contained Thr (869) and/or Thr (885). AR-2 (Thr 875) and AR-5 (Thr 889) were not phosphorylated by the CDPK. These data indicated that Thr 869 (a conserved Thr residue among plant $\mathrm{H}^{+}$-ATPases) and Thr 885 (a unique Thr in OSA2) were phosphorylated by the $55-\mathrm{kDa}$ CDPK in a calcium dependent manner in vitro.

\section{ATPase activity regulation by CDPK phosphorylation}

We discussed about the results of ATPase phospho-

Table 1. CDPK phosphorylated two Thr residues of $\mathrm{H}^{+}$-ATPase auto-regulatory peptides

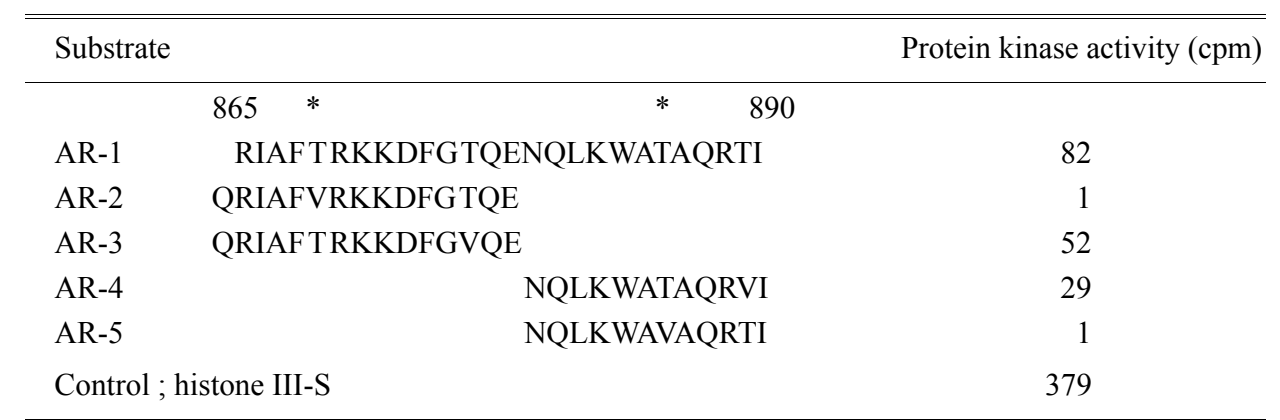

CDPK activity was assayed with each substrate in the presence of $100 \mu \mathrm{M} \mathrm{CaCl}_{2}$. The basal level of substrate phosphorylation was measured in the presence of 4 mM EGTA instead of $\mathrm{CaCl}_{2}$. All assays were means of duplicate determinations from independent experiments.

The AR-1 peptide (865-890) sequence was deduced from the cDNA data.

* : Conserved Thr residues among plant plasma membrane $\mathrm{H}^{+}$-ATPases. 
rylation by the 55-kDa CDPK from two points of view, one from the roles of the CDPK and another from possible ATPase regulation.

Evidence for calcium dependent phosphorylation of ATPase has been accumulated ${ }^{1,3,13,20,21}$. Lino et al. showed that calcium dependent phosphorylation of $\mathrm{H}^{+}$ATPase in beet root led to inhibition of ATPase activity. Kinoshita et al. reported calcium dependent inhibition of ATPase activity in guard cells of fava bean ${ }^{10}$. CDPK phosphorylation residues in other species of the $\mathrm{H}^{+}$ATPase have not been, however, identified yet. In this report, we showed that the 55-kDa CDPK phosphorylated the two Thr residues in the Region I of the rice $\mathrm{H}^{+}$ATPase. The rice 55-kDa CDPK was activated on low temperature treatment ${ }^{12}$ and pathogen infection ${ }^{11}$. Thr (869) and $\mathrm{Thr}(885)$ phosphorylation might couple to $\mathrm{H}^{+}-$ ATPase acitivity modulation on cold stress and pathogen infection. Interestingly, it is reported by Martin et al. that 56-kDa CDPK and OsCPK2, which are membranebound, were activated in response to low temperature ${ }^{14,15}$. These facts raised the possibility that the $55-\mathrm{kDa}$ CDPK in this study might be an OsCPK2-like kinase.

In a reconstituted system, phospholipids have been shown to modulate the $\mathrm{H}^{+}$-ATPase activity and $\mathrm{H}^{+}$-pumping. Lysophosphatidylcholine, which had a positive charge at its hydrophilic region, increased ATPase activity9. These facts suggest that ionic interaction between ATPase and phospholipids appears to play a pivotal role for ATPase activity. Deletion of Region I plus Region II resulted in loss of phospholipid modulation of ATPase activity. The Thr (869) residue is adjacent to a positively charged cluster (RKK). Phosphorylation of the Thr (869) residue can neutralize positive charges around the cluster. This charge change may consequently alter the interaction of the Region I with phospholipids leading to modulation of ATPase activity. In vivo phosphorylation analysis with specific antibodies against phosphothreonine around Thr (869) and Thr (885) will clarify which residues are phosphorylated or dephosphorylated upon ATPase activity regulation. If the phosphorylation on Thr residues is detected in vivo on cold or pathogen infection, mutations on the Thr residues in the $\mathrm{H}^{+}$-ATPase might be a target for breeding cold or pathogen tolerant rice.

\section{Acknowledgements}

We would like to thank Drs. Fritz W. Lischka and Nancy E. Rawson for their critical reading of this manuscript. This work is partly supported by grants from Ministry of Agriculture, Forestry and Fisheries to K. K. and Y. K.

\section{References}

1. Camoni, L. et al. (1998) The plasma membrane $\mathrm{H}^{+}$ATPase from maize roots is phosphorylated in the C-terminal domain by a calcium-dependent protein kinase. Physiol. Plant, 104, 549-555.

2. Chou, P. Y. \& Fasman, G. D. (1978) Prediction of the secondary structure of proteins from their amino acid sequence. Adv. Enzymol. Relat. Areas Mol. Biol., 47, 45148.

3. Desbrosses, G., Stelling, J. \& Renaudin, J. P. (1998) Dephosphorylation activates the purified plant plasma membrane $\mathrm{H}^{+}$-ATPase-possible function of phosphothreonine residues in a mechanism not involving the regulatory C-terminal domain of the enzyme. Eur. J. Biochem., 251, 496-503.

4. Jahn, T. et al. (1997) The 14-3-3 protein interacts directly with the C-terminal region of the plant plasma membrane $\mathrm{H}^{+}$-ATPase. Plant Cell, 9, 1805-1814.

5. Jelich-Ottmann, C., Weiler, E. W. \& Oecking, C. (2001) Binding of regulatory 14-3-3 proteins to the $\mathrm{C}$ terminus of the plant plasma membrane $\mathrm{H}^{+}$-ATPase involves part of its autoinhibitory region. J. Biol. Chem., 276, 3985239857.

6. Kanematsu, M., Dohke, K. \& Ohtsuki, K. (1991) Purification and characterization of three distinct protein kinases from Marchantia polymorpha. Plant Cell Physiol., 32, 159-168.

7. Karibe, H., Komatsu, S. \& Hirano, H. (1996) Partial purification and characterization of a calcium-dependent protein kinase in rice leaves. Phytochemistry, 41, 14591464.

8. Kasamo, K. \& Yamanishi, Y. (1991) Functional reconstitution of plasma membrane $\mathrm{H}^{+}$-ATPase from mung bean (Vigna radiata L.) hypocotyls in liposomes prepared with various molecular species of phospholipids. Plant Cell Physiol., 32, 1219-1225.

9. Kasamo, K. \& Sakakibara, Y. (1995) $\mathrm{H}^{+}$-ATPase from higher plants: functional reconstitution into liposomes and its regulation by phospholipids. Plant Sci., 111, 117131.

10. Kinoshita, T., Nishimura, M. \& Shimazaki, K.-I. (1995) Cytosolic concentration of $\mathrm{Ca}^{2+}$ regulates the plasma membrane $\mathrm{H}^{+}$-ATPase in guard cells of fava bean. Plant Cell, 7, 1333-1342.

11. Komatsu, S. et al. (2004) Alterations by a defect in a rice $\mathrm{G}$ protein alpha subunit in probenazole and pathogeninduced responses. Plant Cell Environ., 27, 947-957.

12. Li, W. \& Komatsu, S. (2000) Cold stress-induced calcium-dependent protein kinase(s) in rice (Oryza sativa L.) seedling stem tissues. Theor. Appl. Genet., 101, 355363.

13. Lino, B., Baizabal-Aguirre, V. M. \& Gonzalez de la Vara, L. E. (1998) The plasma-membrane $\mathrm{H}^{+}$-ATPase from beet root is inhibited by a calcium-dependent phosphorylation. Planta, 204, 352-359.

14. Martin, M. L. \& Busconi, L. (2000) Membrane localization of a rice calcium-dependent protein kinase (CDPK) is mediated by myristoylation and palmitoylation. Plant J., 24, 429-435. 
15. Martin, M. L. \& Busconi, L. (2001) A rice membranebound calcium-dependent protein kinase is activated in response to low temperature. Plant Physiol., 125, 14421449.

16. Ookura, T. et al. (1994) Identification and characterization of a family of genes for the plasma membrane $\mathrm{H}^{+}$ATPase of Oryza sativa L. Plant Cell Physiol., 35, 12511256.

17. Ookura, T. et al. (1995) Active site peptides with CXXC motif on map-resin can mimic protein disulfide isomerase activity. Biochem. Biophys. Res. Comm., 213, 746-751.

18. Palmgren, M., Larsson, C. \& Sommarin, M. (1990) Proteolytic activation of the plant plasma membrane $\mathrm{H}^{+}-$
ATPase by removal of a terminal segment. J. Biol. Chem., 265, 13423-13426.

19. Palmgren, M. et al. (1991) Identification of an autoinhibitory domain in the $\mathrm{C}$-terminal region of the plant plasma membrane $\mathrm{H}^{+}$-ATPase. J. Biol. Chem., 266, 20470 20475.

20. Rutschmann, F. et al. (2002) LeCPK1, a calcium-dependent protein kinase from tomato. Plasma membrane targeting and biochemical characterization. Plant Physiol., 129, 156-168.

21. Schaller, G. \& Sussman, M. (1988) Phosphorylation of the plasma-membrane $\mathrm{H}^{+}$-ATPase of oat roots by a calcium-stimulated protein kinase. Planta, 173, 509-518. 